
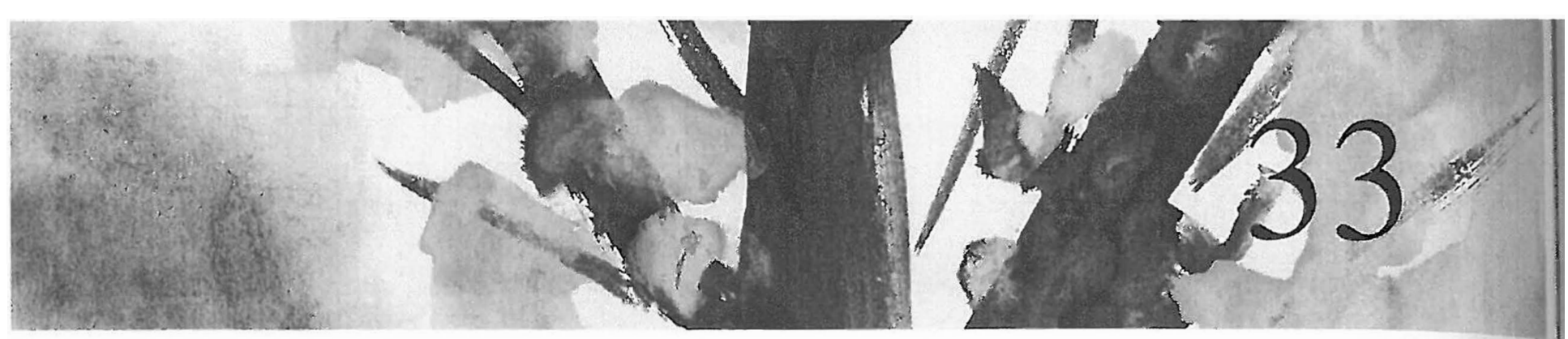

\title{
Indigenizing Outdoor Play in New Zealand: A Conversation Analysis Approach
}

Amanda Bateman, Margie Hohepa and Tim Bennett

\section{INTRODUCTION}

This chapter focuses on a single case analysis of one trip to a local bush reserve in New Zealand. The observations included in this chapter begin by exploring the way in which a promise to the Māori God Tāne Mahuta is managed by the teachers and children at the beginning of the excursion. The promise made is part of the mundane, everyday activity engaged in by these children and teachers during their weekly visit to the bush reserve, where every child is required to recite a phrase that promises not to hurt the creatures, animals or plants of Tāne Mahuta when they are playing in the forest. In the first of the video-recorded episodes, explicit reference to Tāne Mahuta is initially oriented through one of the children reciting the promise, unprompted, at the beginning of the recording. The second observation reveals one of the teachers explaining to a child the rules of entering the forest: that you have to ask permission from Tāne Mahuta before you enter. When a child does not want to say the promise, he is encouraged to do so collaboratively with the teacher before entering the forest. Only once the child has said the promise does he enter, demonstrating the importance of the verbal commitment and participation in the accountable action of promise-making by the participants prior to entering the forest.

Following this initial action of making a promise, the third, fourth and fifth observations provide examples of how reference to Tāne Mahuta was subsequently made on a number of occasions throughout the duration of the excursion. Each time the God of the forest is mentioned, it is with reference to the promise that the children had made when they entered the forest, and how they 
are breaking their promise when they begin to harm the forest environment in their playful activities. The clever ways in which the children attempt to evade the negative consequences of breaking their promise through pretend play is discussed in observations four and five as they use pretend play characters to become 'mud monsters' and 'possums', who are no longer the children who made the promise when they entered the forest.

The chapter discusses how the work of Sacks (1992) and Garfinkel (1967) helps to reveal how the accountable action of making a promise to a Māori God is observable in the teacher-child interactions during outdoor play. Issues such as how teachers structure moral and social order in the New Zealand forest through attending to accountable actions, as well as indigenizing outdoor play through talk about Tāne Mahuta, are discussed. By encouraging the children to protect the natural bush reserve environment during outdoor play excursions, the indigenizing of outdoor play that is specific to the New Zealand context becomes evident, and connections to the early childhood curriculum, Te Whāriki, are made. By analysing the sequential actions involved in the whole excursion, this single case reveals the orderly features of events involved in initiating and maintaining moral order during a teacherchild outdoor excursion. Furthermore, an ethnomethodological approach reveals how these sequences of actions demonstrate how and why reference to a Māori God may be used in everyday teaching and learning with young children in New Zealand.

\section{CONTEXTUAL BACKGROUND}

The early childhood curriculum in New Zealand, Te Whăriki, uses the metaphor of a woven mat where the four principles, empowerment, family and community, holistic development and relationships, are woven with the five curriculum strands, well-being, belonging, contribution, communication and exploration (MoE, 1996). Te Whāriki provides a bicultural framework for teachers and children to work within, affording opportunities for each early childhood centre to build a rich learning space that is sensitive to the needs and aspirations of each child and their family. The importance of a bicultural curriculum was acknowledged as essential when creating the document in recognition of the treaty between Māori and the British Crown, Te Tiriti o Waitangi, where equal respect for both languages and cultures was acknowledged and promoted (Lee et al., 2013). The curriculum document brought with it a vision that each child would have the opportunity to contribute to a democratic society as 'competent and confident learners' (MoE, 1996: 9). This shifted the academic approach from a deficit to a credit perspective of the child, mirroring the philosophical positioning of the image of the child in New Zealand (Carr and May, 1993).

Te Whäriki outlined ways in which children and teachers could work together to coproduce teaching and learning interactions:

This curriculum emphasises the critical role of socially and culturally mediated learning and of reciprocal and responsive relationships for children with people, places, and things. (MoE, 1996: 9)

Through acknowledging the social and cultural ways in which children learn, the curriculum encourages learning opportunities that span across a range of people, including peers, teachers, family and members of the community, and encourages teaching and learning in a range of places, inside and outside of the early childhood centre. The importance for children to experience the outdoor environment on a regular basis is called for where such opportunities 'should be used as learning resources' (MoE, 1996: 83).

Within this context teachers are seen as facilitators of the curriculum. They provide activities and experiences based on children's 
interests and work with and alongside children to help them to understand and create working theories about the various contexts that they live in. Nature-based experiences such as visiting the bush helps children to leam about the natural world. It help children to understand nature, to work with natural materials and to gain affection for the natural world.

Te Whäriki identifies the importance of culture across several dimensions, including language, learning, stories and symbols. The curriculum not only works to support children's positive awareness of their own respective cultural identities, but of other cultures as well. As the indigenous culture to Aotearoa New Zealand, positive awareness and knowledge of Māori cultural knowledge, beliefs and practices in particular are encouraged.

In Māori epistemology the importance of caring for the environment is located in whakapapa (Māori genealogical relationships) and in the personification of natural phenomena (Roberts, 2013). In Māori explanations ${ }^{1}$ of the origins of the universe and the creation of life, all things - animate and inanimate - descend from Ranginui (Rangi or Sky father) and Papatūānuku (Papa or Earth mother), including humankind. Rangi and Papa had many children who each became responsible for different aspects of the natural world. Humankind, as a consequence of genealogical relationships originating with Rangi and Papa, is thus very much a part of the natural environment. From a Māori perspective, the importance of caring for the environment is the same as that of looking after members of one's family.

The relationship between Māori and land provides the clearest, and deepest, expression of what can be termed 'environmental whanaungatanga' or a 'familial relationship' with the other components of the environment (Roberts et al., 1995: 10).

Tāne is considered an important, if not the most important, of the children of Rangi and Papa, reflected in one of the many names he is known by - 'Tāne-nui-a-Rangi' (the greatest son of Rangi). As alluded to above, Tāne is also known as Tāne Mahuta, God of the forest. As Tāne Mahuta he had several wives and his different families of children are evident in the various plant, insect and bird life found in the forest. Tāne Mahuta has the duty and responsibility of watching over and looking after his forest progeny. Māori practices include tikanga (formal protocols) and karakia (ritual chants) for acknowledging and thanking gods such as Tāne Mahuta for access to and use of resources from their respective domains (Marsden and Henare, 2003).

\section{THE PROJECT AND ITS THEORETICAL APPROACH}

The observations considered in this chapter were generated in one early childhood crèche in Hamilton, New Zealand, during 2012 which was funded by a Teaching and Learning Research Initiative (TLRI) (Bateman, 2012a). The project was initiated to find out more about how teaching and learning was socially constructed in everyday conversations between three early childhood teachers and children aged from $2^{1 / 2}$ to 5 years old. This was deemed important as prior research indicated that teachers occasionally felt unsure of when to initiate an interaction with a child if the child was already engaged in an activity, and also how teachers might interact with that child so as not to disrupt their ongoing learning (Peters and Davis, 2011). As teachers had been observed using specific conversational strategies for progressing leaming episodes with children in a prior TLRI study (Carr, 2011), it was also of interest to the present study to try to identify what teaching strategies were used, and the response that a child might give when these strategies were employed.

To gain a closer look at the interactions between teachers and children, the current research took an ethnomethodological approach as the inductive characteristic of 
ethnomethodology affords the emergence of data that guides the researcher and avoids preconceptions that may influence analysis (Garfinkel, 1967). An ethnomethodological lens affords a look at how social situations are co-constructed through the participants' immediate interpretation of events, where a mutual understanding of the interaction is made demonstrable by the participants (Garfinkel, 1967). Garfinkel (1967) followed Goffman's lead in ethnomethodological work (Attewell, 1974), studying social conduct in everyday life and how mundane activity is co-produced and accomplished in accountable ways. Garfinkel states that 'Organised social arrangements consist of various methods for accomplishing the accountability of a setting's organizational ways as a concerted undertaking' (Garfinkel, 1967: 34). This approach to studying social order not only affords a closer look at how social worlds are co-produced by the members present, but also involves an insight into what are assumed normal daily interactions to the people being observed (Silverman, 2006).

In order to reveal how people's verbal utterances co-produced social order, Sacks, Schegloff and Jefferson (1974) analysed the way in which one person's utterance provoked a response from their recipient in a systematic way, facilitated by Jeffersonian transcription conventions. This way of analysing social order through verbal utterances marked the beginnings of conversation analysis (CA). The phenomenon of accountability as a collaborative social achievement was further progressed by Sacks (1992), where verbal utterances were analysed for their accountability; Sacks suggests that when a person performs an action in their talk, others can hold them accountable for that action. It is further suggested in CA that adults perceive young children as finding the concept of causation in accountability difficult to understand. In order to try to understand the social process of causation, Sacks discusses two distinct types of rule formulation with children; Class 1, where 'the consequences naturally follow from the act done' (p. 78), and Class 2, where "you can "get away with" things' (p. 78). Although different, both rule formulations consider the sequential consequence of engaging in an act.

These orderly features of accountable actions as identified by Garfinkel and Sacks are useful when exploring teacher-child interactions where the social organization and moral orders in everyday interactions can be explored, and children's competent ways of contributing can be revealed (for example: Bateman, 2015; Butler, 2008; Church, 2009; Danby, 2002; Danby and Theobald, 2012). CA is now used to explore interactions between young children and their teachers during a routine excursion to a protected bush reserve in New Zealand.

\section{THE ANALYSIS}

As the project was interested in investigating everyday teacher-child interactions, videorecorded episodes of everyday conversations between children and teachers were taken where the teachers took turns to wear a wireless microphone, so that clear audio footage was available for later transcription. The video and audio collection for the entire project resulted in a total of 10 hours of footage. After each episode of data collection, the teacher identified instances within the episode where they felt that teaching and learning had occurred. The researcher made a note of these instances and transcribed and analysed them using conversation analysis.

When conducting the current project, one of the preschool teachers asked if the researcher could follow him on a routine excursion to a local protected bush reserve. As this was one of the everyday places that teachers and children engaged in teaching and leaming interactions, video footage of this excursion was collected, resulting in 1 hour and 40 minutes of footage (the video was paused during lunch time and when children approached a 
microphoned teacher with a sensitive issue such as needing the toilet).

The excursions occurred one day a week with a relatively consistent group of eight children (1:4 ratios of adults to children). The children would transition out one or two at a time, and another child would transition in. This fluid process of change allows for one or two children to learn the customs of the group, the daily routines and the cultural respect surrounding the excursion. The group was dictated by age (18th-10th oldest children), so on average they were about $4 \frac{1}{2}$ years old. This was due to other group activities that happened in the centre. Parents sign a blanket consent form covering the 10 weeks that their child will be attending the excursions, and special permission for antihistamine cream and other medical issues that may compromise child safety during the excursion. Two teachers always attend the trip (one teacher consistent, one rotating) and when possible, parents or other family members come along too. The accompanying teachers attend a defensive driving course to ensure they are responsible drivers (one teacher drives the minibus to and from the bush setting each week) and all qualified teaching staff must have completed a first aid course.

Every individual on the excursion carries a backpack. The children have their lunch, a rain jacket, weather-appropriate clothing and footwear, various exploration tools (magnifying glasses, collection jars etc.) and a small tarpaulin for sitting on in wet weather. The teachers carry a comprehensive first aid kit (and a small one on their belts in the event they have walked away from their backpacks), two large tarpaulins, ropes, cell phones, string, tools, trowel (for digging latrine holes), spare clothing and extra exploration equipment (small microscope, gloves, books, etc.).

Each week the children would decide if they wanted to go to their base camp or go for a hike. At the base camps, structures could be built and worked on over a series of weeks, different areas could be explored and imaginative games were often played. During hikes (destinations were generally decided through democratic processes), the children would lead and the teachers would follow. Children could go as far ahead as they liked as long as they could see a teacher and when they went out of sight, the teachers would call out and the children wait.

The reason for taking the children to the bush was that often children rarely ventured out of the city, let alone into the bush, off the tracks. These excursions not only give the children the opportunity to experience something other than the city, but to gain ownership over a patch of bushland, to build structures out of natural materials and to explore the wonders that nature has to offer. The purpose is for children to gain an appreciation of the natural world, to establish affection for what it has to offer, so that they have a reason to protect it and to live more sustainable lives. There is little point in teaching sustainable practices to children who don't have a reason to care for the natural world.

Once the video recording of the excursion was collected, the teacher-child interactions were transcribed using conversation analysis transcription conventions (see Appendix) to reveal the social organization processes that were being co-produced during the event. This chapter now demonstrates how the preschool teachers and the group of 4-year-old children encourage an awareness of cultural knowledge associated with moral behaviour on the recorded bush walk, where a promise is made to the Māori God Tāne Mahuta, by all members, not to harm the foliage or creatures upon entering the forest area. During the progression of the bush walk, the teachers attend to the accountability of the children's action of making a promise to Tāne Mahuta when they entered the forest; it is a reason for behaving in a moral and respectful way during the bush trip. The following transcriptions and their analysis demonstrate the systematic way in which the accountable action of asking permission and making a promise is present and how an unwillingness by a 
child to abide by their promise is attended to as problematic. Through these actions, the teachers talk the significance of behaving in a culturally responsive way in the outdoor environment into importance, where the teaching and learning interactions are contextually indigenized.

\section{ENTERING THE FOREST}

From the beginning of the video recording of the day trip, the issue of being respectful to the natural bush area was prioritized. This is demonstrated from the start of the trip in this initial interaction (Excerpt 1) between the early childhood teacher, Tim (TIM), and the preschool children Kyber (KBR) and Dylan (DYL). Tim is walking with Kyber and Dylan towards a bridge at the entrance to the forest; a second teacher $(\mathrm{TCH})$ is standing on the bridge talking to more preschool children.

\section{Excerpt 1}

Tim 2nd data collection: Time: 32 seconds

01 TIM: [poor tree $\uparrow$ ]

02 KBR: [个Tane Mahuta] can we come in $\downarrow$ (0.4) we won't hurt

03 your >animals< or your (0.4) creatures or your pl::ants $\downarrow$

$04 \quad(0.8)$ I $\uparrow$ said the wo $\downarrow: r d s: \uparrow$

$05 \mathrm{TCH}$ : I=was=just need to explain to $H \uparrow$ era $\downarrow$ (1.5) when we were

06 on the bridge- $\uparrow$ before we go into Pukemokemoke $\downarrow$ we ask

$07 \quad[()]$

08 ?: [Pukemokemoke]

09 TCH: Pukemokemoke: $\uparrow$ we ask Tāne Mahuta who's the $\downarrow$ God

10 Tof the $\downarrow$ for $\uparrow$ est (0.6) permission to enter his $\uparrow$ forest $\downarrow$

11 TDylan do you want to tell (0.7) Hera what we sa:y $\uparrow$

12DYL: $y^{\prime}$ ave to sa:y $\downarrow$

$>$ Tane $=$ Mahuta $<$ please can we come in

$13{ }^{\circ}>$ an $=$ we $=$ wont $=$ hurt $=$ any $=0$ f $=$ yo ur=animals $<^{\circ}$
On approaching the forest, Kyber immediately begins making his promise to Tāne Mahuta without prompts from any of the teachers present (line 02). The promise that Kyber makes involves a 'collective performative' where the collective pronoun 'we' is used to ask collective permission to enter the forest where it is linked to the specific actions of not hurting animals, creatures or plants (Bateman, 2014). This beginning of the interaction demonstrates Kyber's knowledge of the rules of entering the forest where he independently 'said the words' (line 04) that are needed prior to entering the forest. The clear and immediate reciting of the promise by Kyber demonstrates how being respectful to the outdoor environment has been embedded in practice, and how regular trips to this outdoor environment support respectful cultural knowledge, as promoted in the New Zealand early childhood curriculum, Te Whāriki (MoE, 1996).

Following this, one of the teachers is observed explaining to another child the rules of entering the forest (lines 05-06 and 09-11). Interestingly, rather than having a one-to-one conversation with the child to tell them the rules, the teacher begins her utterance by informing the group about what she is doing and her 'need to explain to Hera' (line 05), drawing attention to this specific action. Informings have been explored in teacher interactions where there is a need to understand more about how teachers use informings 'as a way to attempt knowledge transfer from teacher to student' (Gardner and Mushin, 2013: 79). By looking at how the teacher completes her informing in this instance, we can see that she uses her turn at talk to provide information about the rules around entering the forest, not just to the child who has been identified as unknowing of this rule, but to the whole group. Through passing on knowledge about asking permission from Tāne Mahuta in such a way the teacher ensures that this action is given the attention necessary for all present, attending to the dissemination of this indigenous knowledge as 
important in that place at that time with those people. This action works to implement the bicultural approach to teaching and learning in New Zealand through the Te Whäriki framework where 'The curriculum should include Màori people, places, and artifacts and opportunities to learn and use the Màori language through social interaction' (MoE, 1996: 43).

Through contributing her own knowledge to the situation and then moving on to offer another child the opportunity to add their knowledge to the situation, which he takes as he recites the promise (line 12-13), the teacher affords opportunities for the children to also make a contribution to the teaching and learning situation. This distribution of knowledge about the rules surrounding entering the forest draws on knowledge credit where each member is able to share what they know, further implementing the intentions of Te Whäriki where every child is perceived as capable of contributing knowledge in competent ways.

\section{Excerpt 2}

Tim 2nd data collection: Time: 1 min 20 seconds

14 TIM: D'you ask $\uparrow$ Tane Mahuta if we could come in (0.4)

$15 \downarrow$ Matthew $\uparrow$

16 MTW: o:h: $\downarrow\langle \$ 1$ forgot $\downarrow \$\rangle$

17 TIM: $\quad \mathrm{mm}$ you can ask $\uparrow$ now $\downarrow$

18 MTW: ple::se can=1- [please can I ((walks away from Tim

19 reciting the promise))

20 TIM: [did you ask (0.5) Kaiden $\uparrow$ ((walks towards

21 Kaiden))

22 KDN: <ㅇ don't want to $>$ ((faces the bridge, looking away from

23 Tim))

24 TIM: you don't $\downarrow$ want to $\downarrow$

$25 \quad \mathrm{KDN}:{ }^{\circ} \mathrm{no}^{\circ}$

26 TIM: we need to make sure $\downarrow$ that (0.4) he knows that we're not

27 going to hurt his Ttrees ((crouches down to Kaiden))

28 (0.8)
29 KDN: ${ }^{\circ} \mathrm{no}^{\circ}$

$30 \quad(0.9)$

31 TIM: hmmm

32 KDN: ${ }^{\circ}<n o::>^{\circ} \downarrow$

33 TIM: $\downarrow$ we can say it to $\uparrow$ gether $\downarrow$

$34 \mathrm{KDN}:{ }^{\circ}<$ no:: $>{ }^{\circ} \downarrow$

35 TIM: why not $\uparrow$

36 KDN: coz I don't want to: $\downarrow=$

37 TIM: =did you wake up $\downarrow$ grum $\uparrow$ py $\downarrow$

$38 \quad(2.3)$

39 KDN: IIwant to (1.3) (be) at <m:um:s $\downarrow>^{\circ}$

40 TIM: par $\uparrow$ don

$41 \mathrm{KDN}:$ I=want $\uparrow$ to be at $\downarrow$ mums

42 TIM: $\downarrow$ oh $\downarrow$ (0.7) we'll say it quickly (7.0) me and you (1.0)

43 TTane Mahuta $\uparrow$ (1.1) can we come in to your forest [we]

$44 \mathrm{KDN}:\left[^{\circ}()^{\circ}\right]$

45 TIM: wont hurt any of your tree::s

46 KDN: $\uparrow$ or your <creatures $\downarrow>$

47 TIM: 个or your <creatures $\downarrow>$. 个that's good $\downarrow$. $\downarrow$ right . $\downarrow$ come on

48 do you wanna hold my hand $\downarrow$ ((Kaiden and Tim hold hands

49 and walk into the forest together with Matthew))

At the beginning of Excerpt 2, Tim approaches one of the preschool children, Matthew (MTW), and asks if he has 'asked Tāne Mahuta if we could come in' (line 14), once again drawing attention to the importance of doing this action. Matthew says that he has forgotten and Tim suggests that he can do it 'now' (line 17), placing emphasis on this word marking the immediacy of such an action (Schegloff, 1998). Matthew responds to this urgent action by asking permission without further delay (line 18).

Tim then approaches another child, Kaiden $(\mathrm{KDN})$, asking if he too has asked permission to enter the forest (line 20). This provokes a different response as Kaiden makes it explicit that he does not want to engage with Tim in this talk, verbally and with his physical stance as he avoids eye contact with Tim (Bateman, 2010; Filipi, 2009; Kidwell, 2005). Kaiden's actions assert a disalignment with the current moral order through not engaging in the group activity of asking, prompting Tim 
to attend to this matter as worthy of further attention as he crouches down towards Kaiden and offers an explanation for why asking permission is essential (lines 26-27). When Kaiden still refuses to ask permission, Tim offers a strategy to encourage him as he suggests that they can 'say it together' (line 33). Tim's suggestion here reiterates the activity of asking permission as a collective action that all members have to engage in, and also highlights the importance of Kaiden doing the activity. Through approaching Kaiden's disalignment in such a way, Tim's actions become more direct as he attempts to encourage Kaiden to do something he is resisting. Even though this type of directive could result in a dispute between child and adult (Kent, 2012), as becomes evident in the subsequent lines of talk (lines 34-38), here Tim's offer of doing the action collectively (lines 33 and 42) work to prompt Kaiden to join in. Only when Kaiden has collaboratively achieved asking permission is this episode brought to an end and the trip to the bush reserve is progressed.

Once all children present have asked Tāne Mahuta for permission to enter the forest, the teachers and children all begin their walk. The interactions in Excerpts 3, 4 and 5 occur during various times during the walk.

\section{Excerpt 3}

Tim 2nd data collection: Time: 19 mins 30 seconds

50 IAN: ah lo:ok $\downarrow$ ((points to Matthew who is pulling on a spider

51 web))

52 (1.9) ((Tim looks towards Matthew))

53 TIM: > oh< careful that's a spider web $\downarrow$ (1.1) you wouldn't want

54 to break the spider's home would you $\uparrow$ ( reaches towards

55 the web that Matthew is still holding on to))

56 MTW: $<$ no:: $>\downarrow$

57 TIM: $<$ no:: $>\downarrow$ so you [don't have to pull tha: $t \downarrow]$
58 MTW: [I'm just going to-] I'm just going to-=

59 TIM: =that's lovely gentle hands $\uparrow$

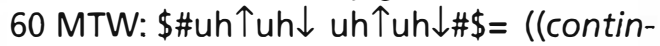
ues pulling gently on the web.

61 Looks towards Jenny))

$62 \mathrm{TIM}:=\mathrm{mmm} \downarrow=$

63 MTW: $=\$ \downarrow \downarrow^{\prime} m$ m just $\downarrow$ shaking $\uparrow$ it hhh $\$$

64 TIM: you might be giving the spider a headache $\downarrow$

65 MTW: I'm pulling it up and d个own $\downarrow$

66 TIM: $\uparrow$ right (0.3) lets go $\downarrow$ oh oh see you've pulled it out

67 ((as they start to walk away the web falls to the

68 ground))

69 MTW: I didn't $\uparrow$ ( )

70 TIM: you need to be more $\downarrow$ careful because you prômised Tāne

71 Mahuta $\downarrow$ that you wouldn't hurt his $\uparrow$ things $\downarrow$ (0.7) his

$72 \quad$ creatures and his pla:nts $\downarrow$

73 IAN: $\uparrow$ or his <spi:ders $\downarrow>$

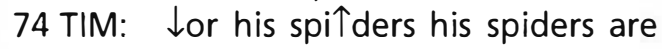
some of his crea: $\uparrow$ tures $\downarrow$

75 IAN: [or ( )]

76 MTW: [what about his \$co:ws\$] hhh (0.8) what about his cows $\downarrow$

77 TIM: $\uparrow$ Tāne Mahuta didn't make any $<\downarrow c o: w s \uparrow>$

78 MTW: \$da:h: why didn't he make any $<\downarrow c o: w s \uparrow>\$$

79 TIM: $\downarrow$ cows came from $>$ Eu $\uparrow$ rope $<$

During their walk, one of the children, Ian, draws attention to Matthew, who is pulling a spider's web. Tim looks towards Matthew and immediately advises him to be careful and then leaves a brief pause before offering a more empathic strategy suggesting that he might break the spider's 'home' (line 54) and give the spider a 'headache' (line 64). Matthew's sequential response to this strategy is to continue to pull gently at the web and when the group starts to walk on Tim draws this part of the episode to a close with his utterance 'right' (Schegloff and Sacks, 1973) and then with a collective action to leave, 'let's go' (line 66) (Butler, 2008). However, at this point the spider's web breaks and falls to the ground, prompting Tim to refer to the earlier promise 
that Matthew had made to Tāne Mahuta, quoting specific words of the promise. Tim suggests to Matthew that through making his promise he is to be held accountable for his subsequent actions (lines 70-72), as the promise he made to Tāne Mahuta had strategic and sequential consequences and considerations (Sacks, 1992). Through attending to Matthew's action as problematic, Tim ensures that the children are being respectful to the natural bush environment and that cultural practices are adhered to by this group of young children during their excursion. This return to indigenous practices then prompts further discussion between Tim and the children about what constitutes the 'creatures' of Tāne Mahuta, further advancing knowledge around this topic in relation to the outdoor environment.

So far during this outdoor bush excursion the children and teachers engaged in a collaborative action of asking Tāne Mahuta for permission to enter the forest, drawing attention to the importance of being respectful to Māori cultural practices, and practically implementing the bicultural New Zealand early childhood curriculum (Excerpts 1 and 2). Once everyone had made their promise this action was referred back to when it appeared that a child was not being respectful to the outdoor environment in his play (Excerpt 3). In Excerpts 4 and 5 we see how children resist being reprimanded for being disruptive to the outdoor environment through the employment of pretend play characters.

\section{Excerpt 4}

Tim 2nd data collection: Time: 1 hour 18 mins 45 seconds

80 KBR: I'm a $\downarrow$ possum $\uparrow$ ((grabs leaves and throws them into the

81 stream))

82 JKS: well I'm not going that far ((points to the

83 stream))

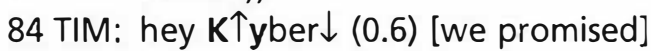
$85 \mathrm{KBR}$ : [I'm not Kyber]
$86 \quad(3.1)$

87 TIM: well you promised Tāne Mahuta you weren't going to

88 hurt (0.5) >his=things $\downarrow<$ and Tthrowing- (0.8) throwing

89 bra:nches is not (0.6) being respectful $\downarrow$

90 JKS: well I'm not gonna throw them 个ei:ther $\downarrow$

91 TIM: that's good $\downarrow$

92 JKS: >because $<$ I'm $\uparrow$ not gonna break $<\uparrow m: y:>$ prom Lise

93 TIM: .hhh I know you're being a possum (0.3) and that is

94 the sort of thing that possums do (1.2) but um

95 (1.0) you did promise [Tāne that you wouldn't hurt

96 it]

In the interaction in Excerpt 4, Kyber begins throwing leaves into a nearby stream whilst also announcing that he is 'a possum' (lines 80-81), combining verbal action and gesture to maximize understanding (Bateman, 2012b). Tim responds to this action by calling Kyber's name to secure his attention (line 84), 'inflected with a prosodic contour that we might describe as waming' (Potter, 2012: 1), followed by a brief pause before Kyber and Tim overlap their talk. During this overlap Tim begins to refer to the promise that Kyber made and Kyber asserts that he is no longer 'Kyber' (the child who made the promise). There is a significant pause before Tim responds by giving an extended turn of talk, reminding Kyber that he made a promise to Tāne Mahuta and suggesting that his actions are not 'being respectful' (line 89). There is a brief interaction between the teacher and another child where the child conveys her opposing stance to Kyber's actions, followed by Tim reassuring Kyber that he knows that Kyber is 'being a possum' and 'that is the sort of things that possums do' (lines 93-96). Tim responds by telling Kyber that, although Kyber's actions are acceptable for a possum, they are not acceptable for someone who has made a promise to Tāne Mahuta to be respectful to the environment. Here, Tim takes this 
opportunity to teach about the importance of respecting cultural traditions during these outdoor play activities.

This initial sequence of interaction reveals how Tim attends to the act of making the promise as an accountable action (Sacks, 1992) when one child becomes destructive to the forest foliage. In response to a name calling from the teacher in the form of a warning, the child uses pretence to try to evade the negative consequences of breaking his promise. This demonstrates the child's clever way of possibly avoiding the consequences of his action through pretend play, as being destructive to the protected bush reserve is something that possums 'do'. Therefore, being a possum means that he can no longer be held accountable for breaking the promise that he made when he was a child entering the forest. Children's pretend play shows how competently specific roles are used as interactional devices to co-produce authority and subordinance in disputes (Cobb-Moore, 2012). These findings are mirrored here where a specific character was invoked to justify destructive and incompliant behaviour and to avoid being accountable for a prior action.

Tim's monitoring of the ways in which the children act within the environment here demonstrates the implementation of Te Whäriki and the importance of caring for the environment, as well as also teaching about the wider cultural heritage of taking care of the land.

\section{Excerpt 5}

Tim 2nd data collection: Time: 1 hour 25 mins 10 seconds

Tim and Jackson are sitting on a tree. Kyber approaches them and asks Tim if he will be involved in a game. As he does so Kyber swings on the tree that Tim and Jackson are sitting on. The following occurs:

\section{JKS: <sto:::p> ((looks at Kyber $))$ \\ 118 TIM: >K $\uparrow$ yber $\downarrow<(0.7)$ are [you listening $\uparrow]$}

119 KBR: [I'm not Kyber $\downarrow$ ] I'm not Kyber 120 TIM: you're the mud monster $\downarrow$
$121 \mathrm{KBR}:$ yeah $\downarrow$

122 TIM: Jackson is asking you to stop

$123 \quad$ (2.4)

124 KBR: ((looks at Tim and pulls some bark off the tree))

125 TIM: please stop pulling the trees apart $\downarrow$ Kyber $\uparrow$ (1.1) you

126 promised Tảne Mahuta that you $\uparrow$ wouldn't hurt his $\downarrow$ trees

127 and you have been- (0.5) been very de $\uparrow$ structive $\downarrow$ since we

$128 \mathrm{~g} \uparrow$ ot to the playground $\downarrow$

129 KBR: ((stops pulling the bark and looks down then walks

130 away towards a group of children))

As with the prior interaction, in Excerpt 5 Tim uses Kyber's name with emphasis and inflection on the calling, marking a warning tone (line 118) (Potter, 2012), indicating that he has something important to say so Kyber should be listening. Also as before, Kyber responds by stating that he is 'not Kyber' (line 119) and this time Tim is the one to identify the character that Kyber now is, the 'mud monster', indicating that they are both knowledgeable about this play and associated roles prior to this moment. At first, Tim reiterates the intentions of another child on the tree, suggesting that Kyber needs to stop as the other child has already asked him to. However, this does not stop Kyber as he then begins to pull bark off the tree (line 124), and so Tim once again returns to the promise that Kyber made as Tim makes a contrast to Kyber's promise and his current behaviour being a contradiction to this as he is identified as being 'very destructive' (line 127). Through these actions Tim attends to the activity of being respectful to the bush environment as paramount, where destructive behaviour is oriented to as unacceptable. In doing so he consistently manages a culturally responsive outdoor play experience for the children where Tāne Mahuta is talked into importance regularly to familiarize the children with the Māori God in a contextual way. 


\section{DISCUSSION OF THE METHODOLOGICAL APPROACH}

As stated earlier in this chapter, this research followed an ethnomethodological approach in order to understand what was happening for the children during their routine excursion to the local forest, and the play activities that may have been afforded there. By applying an inductive approach, the underlying issues surrounding cultural sensitivity in pedagogical practice were found embedded within the visit as a mundane activity that worked to indigenize outdoor play. The organizational ways of doing 'outdoor play' in the bush as a joint accomplishment by the members present was observable, affording insight into the everyday activity (Garfinkel, 1967). The ethnomethodological approach not only revealed the orderly features of the members at play, but also how the implementation of the bicultural curriculum Te Whäriki was enacted in sociocultural ways, through making reference to a Māori God. The broader theme of the local management of the setting (Garfinkel, 1967) was made visible through explicit orientation to accountability, where the children were held accountable for making a promise and holding true to that promise.

Transcribing and analysing the verbal and nonverbal actions of the children and teacher using CA revealed the systematic ways that the moral and social order was attended to during the outdoor play excursion. The co-production of accountability was made observable through the turns at talk and gesture, where each participant - teacher and child - had to work collaboratively in performing the task of making a promise, making it visibly significant at that time, in that place and with those people. The systematic ways that accountability was performed also became visible, initially through the child making their promise, either alone (Excerpt 1) or with prompts from another (Excerpt 2), which were then oriented back to by the teacher to assert accountability to the children when they performed an action that was in conflict to their promise. The knowledge distribution around rules of appropriate behaviour when playing in the outdoor environment became clear through CA transcription, where pauses in the talk afforded opportunities for the children to contribute their own knowledge in competent ways.

\section{CONCLUSION}

The project from which this footage emerged aimed to explore how pedagogical interactions were locally managed in everyday teaching and learning interactions by children and their teachers in New Zealand (Bateman, 2012a). This chapter has focused on a single case analysis of everyday interactions during a routine outdoors excursion that demonstrated pedagogy embedded in cultural practice. The methodological approach of ethnomethodology and conversation analysis has provided insight into what the children and teachers attend to as having pedagogical significance.

The transcriptions capture the sequence of events that took place from the start of the excursion and instances of pretend play that children cleverly used to avoid consequences of non-compliant behaviour. Although the children invoked pretend play characters such as mud monsters and possums, their teacher, Tim, consistently attended to the importance of being culturally respectful in their actions. Through attending to respectful ways of being in outdoor play in New Zealand, the teacher can be observed indigenizing pedagogical practice in this specific context. The importance of passing on cultural knowledge and ways of being in a routine, everyday way and how this is achieved is revealed, holding implication for teachers concerned with how to achieve such practice within the bicultural framework of $\mathrm{Te} \mathrm{Wh}^{-}$ariki. 


\section{Note}

1 Explanations vary in detail across iwi (tribes).

\section{REFERENCES}

Attewell, P. (1974) 'Ethnomethodology since Garfinkel'. Theory and Society, 1 (2): 179-210.

Bateman, A. (2010) Children's co-construction of context; prosocial and antisocial revisited. Unpublished PhD Thesis., University of Wales Swansea, Wales.

Bateman, A. (2012a) Pedagogical Intersubjectivity: Teaching and Learning Conversations between Children and Teachers. Wellington, New Zealand: NZCER.

Bateman, A. (2012b) 'When verbal disputes get physical'. In S. Danby and M. Theobald (eds), Disputes in Everyday Life: Social and Moral Orders of Children and Young People (Sociological Studies of Children and Youth, 15). Bradford: Emerald Insight. pp. 267-96.

Bateman, A. (2014) 'Young children's English use of we in a primary school in Wales'. In Theodossia-Soula Pavlidou (ed.), Constructing Collectivity: We Across Languages and Contexts. Amsterdam: John Benjamins. pp. 361-91.

Bateman, A. (2015) Conversation Analysis and Early Childhood Education: The Co-production of Knowledge and Relationships. Farnham: Ashgate.

Butler, C.W. (2008) Talk and Social Interaction in the Playground. Farnham: Ashgate.

Carr, M. (2011) 'Young children reflecting on their learning: Teachers' conversation strategies'. Early Years: An International Journal of Research and Development, 31 (3): 257-70.

Carr, M. and May, H. (1993) 'Choosing a model. Reflecting on the development process of Te Whāriki: National Early Childhood Curriculum Guidelines in New Zealand'. International Journal of Early Years Education, 1 (3): 7-21.

Church, A. (2009) Preference Organisation and Peer Disputes: How Young Children Resolve Conflict. Aldershot: Ashgate.

Cobb-Moore, C. (2012) "'Pretend I was Mummy": Children's production of authority and subordinance in their pretend play interaction during disputes'. In S. Danby and M. Theobald (eds), Disputes in Everyday Life: Social and Moral Orders of Children and Young People (Sociological Studies of Children and Youth, 15). Bradford: Emerald Insight. pp. 85-118.

Danby, S. (2002) 'The communicative competence of young children'. Australian Journal of Early Childhood, 27 (3): 25-30.

Danby, S. and Theobald, M. (eds) (2012) Disputes in Everyday Life: Social and Moral Orders of Children and Young People (Sociological Studies of Children and Youth, 15). Bradford: Emerald Insight.

Filipi, A. (2009) Toddler and Parent Interaction: The Organisation of Gaze, Pointing and Vocalisation. Amsterdam: John Benjamins.

Gardner, R. and Mushin, I. (2013) 'Teachers telling: Informings in an early years classroom'. Australian Journal of Communication, 40 (2): 63-82.

Garfinkel, H. (1967) Studies in Ethnomethodo/ogy. Oxford: Prentice-Hall.

Kent, A. (2012) 'Compliance, resistance and incipient compliance when responding to directives'. Discourse Studies, 14 (6): 711-30.

Kidwell, M. (2005) 'Gaze as social control: How very young children differentiate "the look" from a "mere look" by their adult caregivers'. Research on Language and Social Interaction, 38 (4): 417-49.

Lee, W., Carr, M., Soutar, B. and Mitchell, L. (2013) Understanding the Te Whāriki Approach: Early Years Education in Practice. New York: Routledge.

Marsden, M. and Henare, T.A. (2003) 'Kaitiakitanga: A definitive introduction to the holistic world view of the Maori'. In C. Royal (ed.), The Woven Universe: Selected Writings of Rev. Māori Marsden. Wellington: Te Wānanga-o-Raukawa. pp. 54-72.

MoE (Ministry of Education) (1996) Te Whāriki: He Whāriki Mātauranga mō ngā Mokopuna o Aotearoa. Early Childhood Curriculum. Wellington: Learning Media.

Peters, S. and Davis, K. (2011) 'Fostering children's working theories: Pedagogic issues and dilemmas in New Zealand'. Early Years, 31 (1): 5-17.

Potter, J. (2012) Discourse analysis and discursive psychology. In H. Cooper (ed.), Handbook of Research Methods in 
Psychology: Vol. 2. Quantitative, Qualitative, Neuropsychological, and Biological. Washington, DC: American Psychological Association Press. pp. 111-30.

Roberts, M. (2013). Ways of Seeing: Whakapapa. Sites: New Series, 10(1), 93-120.

Roberts, Mere, Norman, Waerete, Minhinnick, Nganeko, Wihongi, Del and Kirkwood, Carmen (1995) Kaitiakitanga: Maori Perspectives on Conservation. Pacific Conservation Biology, 2 (1): 7-20. Available from http://search.informit.com.au.ezproxy. waikato.ac.nz/documentSummary; $d n=7543009$ 23622812; res=IELHSS> ISSN: 1038-2097.
Sacks, H. (1992) Lectures on Conversation, Vols I and II. Oxford: Blackwell.

Sacks, H., Schegloff, E.A. and Jefferson, G. (1974) 'A simplest systematics for the organisation of turn-taking for conversation'. Language, 50: 696-735.

Schegloff, E.A. (1998) 'Reflections on studying prosody in talk-in-interaction'. Language and Speech, 41 (3-4): 235-63.

Schegloff, E.A. and Sacks, H. (1973) 'Opening up closings'. Semiotica, 8 (4): 289-327.

Silverman, D. (2006) Interpreting Qualitative Data: Methods for Analysing Talk, Text and Interaction. London: Sage. 


\section{APPENDIX}

\section{CA Transcription Conventions}

The conversation analysis symbols used to transcribe the data are adapted from Jefferson's conventions described in Sacks, Schegloff and Jefferson (1974).

[ the beginning of an overlap

] the end of an overlap

- breaking off from an utterances

= the equals sign at the end of one utterance and the beginning of the next utterance marks the latching of speech between the speakers. When used in-between words it marks the latching of the words spoken in an utterance with no break.

(0.4) the time of a pause in seconds

$::$ lengthening of the prior sound. More or fewer colons are used to represent the longer or shorter lengthening $\uparrow$ a rising intonation in speech

$\downarrow$ a falling intonation in speech

Underscore marks an emphasis placed on the underscored sound

Bold words which are underscored and bold indicate heavy emphasis or shouting

${ }^{\circ}$ degree sign ${ }^{\circ}$ either side of a word indicates that it is spoken in a quiet, soft tone

(brackets) utterance could not be deciphered

((brackets)) double brackets with words in italics indicate unspoken actions

.hhh audible in-breath

\# creaky voice

$\$$ smile talk

$><$ spoken quickly

$<>$ drawn out speech

: extended

hhh laugh 